\title{
IONIZING RADIATION SENSITIZES LEUKEMIC MOLT-4 CELLS TO TRAIL-INDUCED APOPTOSIS
}

\author{
Martina Řezáčová 1 , Jiřina Vávrová $a^{3}$, Doris Vokurková ${ }^{2}$
}

Charles University in Prague, Faculty of Medicine and University Hospital Hradec Králové, Czech Republic: Department of Medical Biochemistry ${ }^{1}$, Institute of Clinical Immunology and Allergology2; University of Defense, Faculty of Military Health Sciences, Hradec Králové, Czech Republic ${ }^{3}$

Summary: One of perspective approaches in treatment of hematological malignancies is activation of death receptors for TRAIL. However, leukemia cells studied to date have shown variable susceptibility to TRAIL. Our study demonstrates that cells of acute T-lymphoblastic leukemia MOLT-4 are resistant to TRAIL and that ionizing radiation in the therapeutically achievable dose of 1 Gy sensitizes TRAIL-resistant cells MOLT-4 to the TRAIL-induced apoptosis by increase in death receptors for TRAIL DR5. When TRAIL is applied after the irradiation in the time of increased DR5 positivity more efficient cell killing is achieved.

Key words: TRAIL; Leukemia; Ionizing radiation; DR5; Apoptosis

\section{Introduction}

Therapeutic strategies that target tumor cells without compromising normal tissue function are being intensively sought. One such perspective approach in treatment of hematological malignancies is activation of so called death receptors. The family of death receptors include Fas (CD95), tumor necrosis factor receptor (TNFR), death receptor 3 (DR3/wsl-1), death receptor 4 (DR4, TRAIL-R1) (11) and death receptor 5 (DR5, TRAIL-R2) (15). Of these the most promising are DR4 and DR5, the receptors for tumor necrosis factor-related apoptosis inducing ligand - TRAIL. By binding to these receptors, TRAIL, or its agonists, activate extrinsic apoptotic pathway. They induce trimerization of the receptor and recruitment of Fas-associated death domain adaptor protein (FADD). FADD in turn recruits caspase 8 and 10. This complex is called DISC - death inducing signaling complex. Within this complex caspase $8 / 10$ is activated, which triggers apoptosis $(1,2,10)$.

An alternative pathway for apoptosis onset is the intrinsic pathway (12). The intrinsic apoptotic pathway is triggered in response to DNA damage, of which the most severe are double-strand breaks of DNA (DSB). Recognition of DSB causes an increase in and activation of p53 and affects the balance of proapoptotic and antiapoptotic members of the Bcl-2 family, resulting in release of cytochrome $\mathrm{c}$ from mitochondria and activation of caspase 9. A typical factor which induces apoptosis by activation of intrinsic pathway is ionizing radiation (IR).

However, these pathways do not work independently. Induction of apoptosis through the extrinsic pathway can be controlled by regulation of the amount of proteins required for DISC formation, mainly DR4 and DR5. Through the activation of various transcription factors, the expression of DR4 and DR5 can increase followed by the induction of apoptosis (7). Treatment of cancer cells with glucocorticoids and interferon gamma can increase DR5 expression in cells with mutated p53 (9). Many transcription factors seem to be involved in transcriptional control of TRAIL receptors, e.g. NFKB, p53, STAT1 (5). TRAIL has been found to kill cancer cells selectively, with low toxicity to normal cells. TRAIL induces apoptosis in many haematological malignancies (i.e. acute lymphatic, myeloid and promyelocytic leukemia). Unfortunately, in vitro resistance to TRAIL-induced apoptosis in hematological malignancies has been observed and TRAIL may thus have only a limited role as a single agent for these cancers (18).

It has been shown previously that antileukemic drugs such as etoposide and Ara-C can induce DR5 increase in leukemia cells and sensitize the cells to TRAIL effects (3, $16,17)$. Also, IR caused significantly enhanced positivity of DR5 receptor $24 \mathrm{~h}$ after higher dose irradiation (6 and 8 Gy) of TRAIL-sensitive cells of promyelocytic leukemia HL-60. In these cells preincubation with TRAIL also led to an increase in proapoptotic t-Bid and decrease of antiapoptotic Mcl-1 and increased IR-induced apoptosis (13).

Now we are studying the effect of IR, a known activator of the intrinsic apoptotic pathway, on the amount of DR5 receptor in T-lymphocyte leukemic cells MOLT-4 and we are exploring the effect of the combination of TRAIL and IR on cell death and apoptosis induction. 


\section{Materials and Methods}

\section{Cell culture and culture conditions}

MOLT-4 cells were obtained from American Type Culture Collection (University Blvd., Manassas, USA). The cells were cultured in Iscove's modified Dulbecco's medium (Sigma) supplemented with $20 \%$ fetal calf serum, $0.05 \%$ L-glutamine, $150 \mathrm{UI} / \mathrm{ml}$ penicillin, $50 \mu \mathrm{g} / \mathrm{ml}$ streptomycin in humidified incubator at $37^{\circ} \mathrm{C}$ and controlled $5 \% \mathrm{CO}_{2}$ atmosphere. The cultures were divided every $2^{\text {nd }}$ day by dilution to a concentration of $2 \times 10^{5}$ cells $/ \mathrm{ml}$. Cell counts were performed with a hemocytometer. Cell membrane integrity was determined using the Trypan Blue exclusion technique. Cells in the maximal range of 20 passages were used for this study.

\section{Gamma irradiation}

Aliquots of $10 \mathrm{ml}$ of cell suspension $\left(2 \times 10^{5} / \mathrm{ml}\right)$ were plated into $25 \mathrm{~cm}^{2}$ flasks (Nunc) and irradiated at room temperature using ${ }^{60} \mathrm{Co} \gamma$-ray source with a dose-rate of 0.5 $\mathrm{Gy} / \mathrm{min}$ at a distance of $1 \mathrm{~m}$ from the source. After the irradiation the flasks were placed in a $37{ }^{\circ} \mathrm{C}$ incubator with $5 \% \mathrm{CO}_{2}$ and the aliquots of the cells were removed at various times after irradiation for analysis. The cells were counted and cell viability was determined with the Trypan blue exclusion assay.

\section{TRAIL (TNF-related apoptosis-inducing ligand)}

For the experiments, Killer TRAIL ${ }^{\mathrm{TM}}$ (Alexis, Germany) was used. TRAIL was diluted in HEPES buffer $\mathrm{pH}$ 7.7, containing $300 \mathrm{mM} \mathrm{NaCl}, 0.006 \%$ Tween $20,1 \%$ sucrose, $0.5 \mathrm{mM}$ DTT (dithiotreitol).

\section{Cell cycle analysis}

The cells were collected and washed with a cold PBS (phosphate buffered saline) and fixed with $70 \%$ ethanol. For the fixation of low molecular fragments of DNA the cells were incubated for $5 \mathrm{~min}$ at room temperature in a phosphate buffer and then stained with a propidium iodide (PI) in the Vindelov's solution for 30 minutes at a temperature of $37{ }^{\circ} \mathrm{C}$. The fluorescence (DNA content) was measured with the Coulter Electronic (Hialeah, FL, USA) apparatus. A minimum of 10,000 cells analyzed in each sample has served to determine the percentages of cells in each phase of the cell cycle using the Multicycle software.

\section{DR5 and CD7 antibody, apoptosis detection}

For apoptosis detection we used Apoptest-FITC kit (DakoCytomation, Brno, Czech Republic). During apoptosis, cells expose phosphatidylserine at the cell surface. Annexin $\mathrm{V}$ is a phospholipid binding protein which, in the presence of calcium ions, binds selectively and with high affinity to phosphatidylserine. For detection of CD7 surface marker we used PE-conjugated anti-human CD7-PE (8H8.1, IgG2b-IM1429) obtained from Immunotech (Marseille, France). For detection of TRAIL receptor DR5, mAb

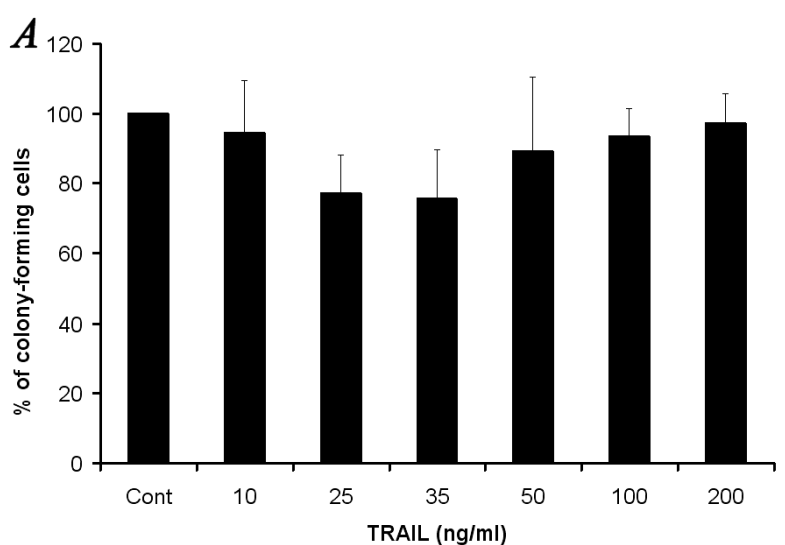

$B$

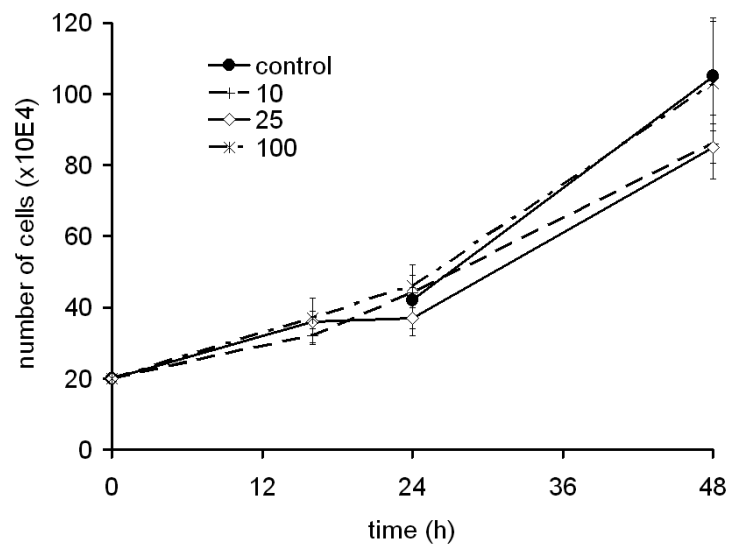

C

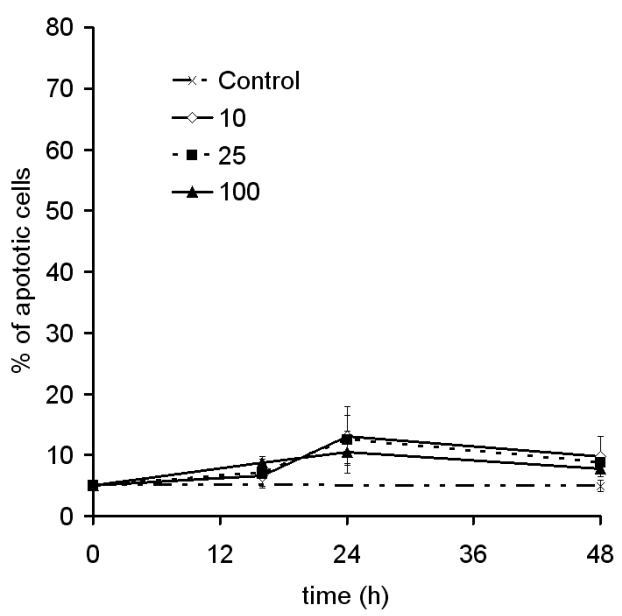

Fig. 1: Effect of TRAIL on MOLT-4 cells.

A: Colony-forming assay. The colonies (containing 40 or more cells) were counted after 14 days of incubation in $5 \%$ $\mathrm{CO}_{2}$ at $37^{\circ} \mathrm{C}$.

B: Proliferation of the cells in medium containing 10, 25 or $100 \mathrm{ng} / \mathrm{ml}$ TRAIL

C: Apoptosis induction by 0,25 or $100 \mathrm{ng} / \mathrm{ml}$ TRAIL determined by flow-cytometric analysis during $48 \mathrm{~h}$ of exposure. The data represent mean values from three experiments \pm standard deviation. TRAIL did not have significant effect ( $\mathrm{p}>0,1$ by Students' T-test). 
to DR5 clone HS201 (obtained from Alexis, Germany) was used. The cells were incubated with $\mathrm{mAb}$ for $15 \mathrm{~min}$ at room temperature. Then the cells were washed with PBS containing $5 \% \mathrm{FCS}$ and $0.02 \% \mathrm{NaN}_{3}$ and incubated with anti-mouse $\mathrm{IgG}(\mathrm{Fc} \gamma)$-PE (obtained form Beckman-Coulter, USA) for $15 \mathrm{~min}$ at room temperature. Flow cytometric analysis was performed on a Coulter Epics XL flow cytometer equipped with a $15 \mathrm{~mW}$ argon-ion laser with excitation capabilities at $488 \mathrm{~nm}$ (Coulter Electronic, Hialeah, FL, USA). A minimum of 10000 cells was collected for each sample in a list mode file format.

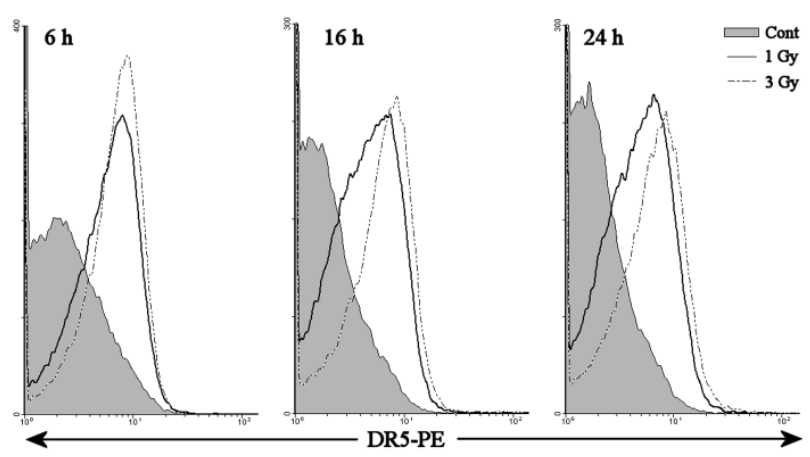

Fig. 2: Increase of DR-5 receptors after irradiation.

MOLT-4 cells were exposed to 1 or 3 Gy of gamma radiation and changes in amount of DR5 were evaluated by flowcytometry 6,16 and $24 \mathrm{~h}$ after the irradiation.

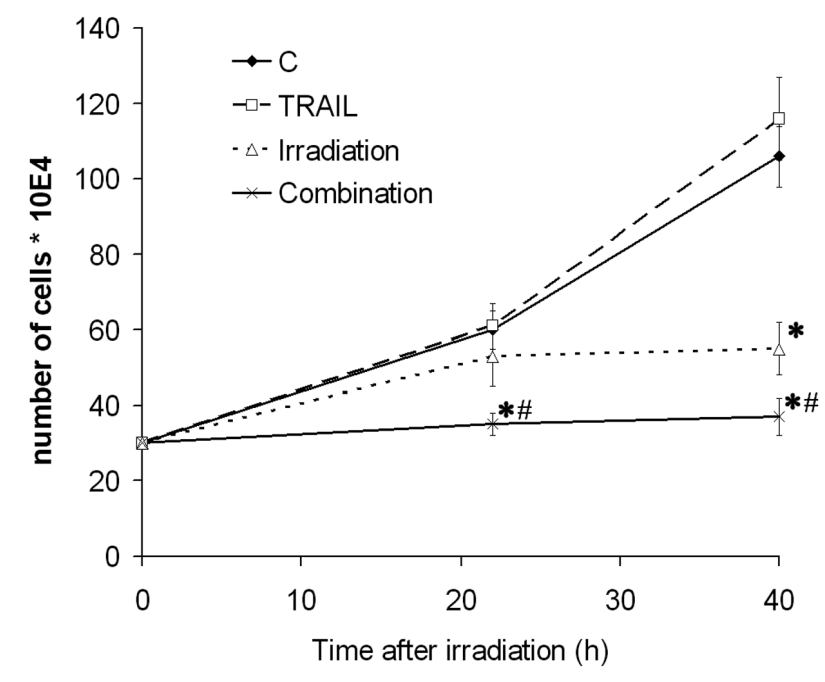

Fig. 3: Combined effects of irradiation and TRAIL on cell proliferation.

MOLT-4 cells were irradiated by the dose of $1 \mathrm{~Gy}$ and TRAIL in final concentration $100 \mathrm{ng} / \mathrm{ml}$ was added to the culture medium $16 \mathrm{~h}$ after the irradiation. The data represent mean values from three experiments \pm standard deviation.

*: significantly different to control; \#: significantly different to irradiation alone ( $p<0,01$ by Students' T-test).

\section{Statistical analysis}

The results were statistically evaluated with Student's ttest. The values represent mean $\pm \mathrm{SD}$ (standard deviation of the mean) from three independent experiments. Statistical significance of the difference of means in comparable sets is indicated in figures.

\section{Results}

\section{MOLT-4 cells are resistant to TRAIL}

TRAIL itself has no significant long-term effect on MOLT-4 cells. Incubation with TRAIL did not significantly reduced proliferation rate of MOLT-4 cells (Fig. 1B), did not significantly reduce the number of cells forming colonies (Fig. 1A) and did not induce apoptosis (Fig. 1C). Using flow cytometric detection, only $7 \%$ of control MOLT- 4 cells are positive for DR5 receptor.

\section{Irradiation causes increase of DR5 receptors}

We evaluated changes in expression of TRAIL DR5 receptors after exposure of MOLT-4 cells to different doses of ionizing radiation. As shown in Fig. 2, ionizing radiation induced a significant increase of DR5 receptors after irradiation with doses of 1 and $3 \mathrm{~Gy}$, as detected by flow cytometry 6 to 24 hours after irradiation. The increase in DR5 was already apparent $6 \mathrm{~h}$ after the irradiation (C $7.1 \%$, 1 Gy $35.8 \%$, 3 Gy $45.7 \%$ ), rose further at 16 h (C $6.3 \%$, 1 Gy $40.7 \%$, 3 Gy $59.8 \%$ ) and the DR5 positivity persisted also at 24 h (C $6.9 \%, 1$ Gy $44.1 \%, 3$ Gy $60.4 \%)$.

\section{Irradiation sensitizes MOLT-4 cells to TRAIL-induced apoptosis}

As the difference between DR5 positivity $16 \mathrm{~h}$ and $24 \mathrm{~h}$ after irradiation was not considerable, we decided to add TRAIL to the culture medium $16 \mathrm{~h}$ after the irradiation. The cells were irradiated with the dose of $1 \mathrm{~Gy}$ and 16 hours later TRAIL was added to culture medium in a final concentration of $100 \mu \mathrm{g} / \mathrm{l}$. Combination of these two factors caused significantly more intensive proliferation arrest (Fig. 3) and induced apoptosis in a higher percentage of cells in the comparison to only irradiated cells, as detected by Annexin V binding (IR $41 \%$, IR+TRAIL $52 \%$; $40 \mathrm{~h}$ after the irradiation - Fig 4A) and DNA content analysis (IR $22 \%$, IR+TRAIL $33 \%$; $40 \mathrm{~h}$ after the irradiation - Fig. 4B). The cells were losing CD7 positivity during apoptosis. Fig. 5 shows the changes of CD7 positivity and Annexin V binding $22 \mathrm{~h}$ after the irradiation.

\section{Discussion}

The therapy of human leukemia has experienced great advances during recent years. However, as for leukemias of lymphocytic origin, chronic lymphocytic leukemia is considered a resistant disease that desperately needs new therapeutical strategies and adults with acute lymphoblastic leukemia almost universally relapse after conventional chemotherapy (7). 


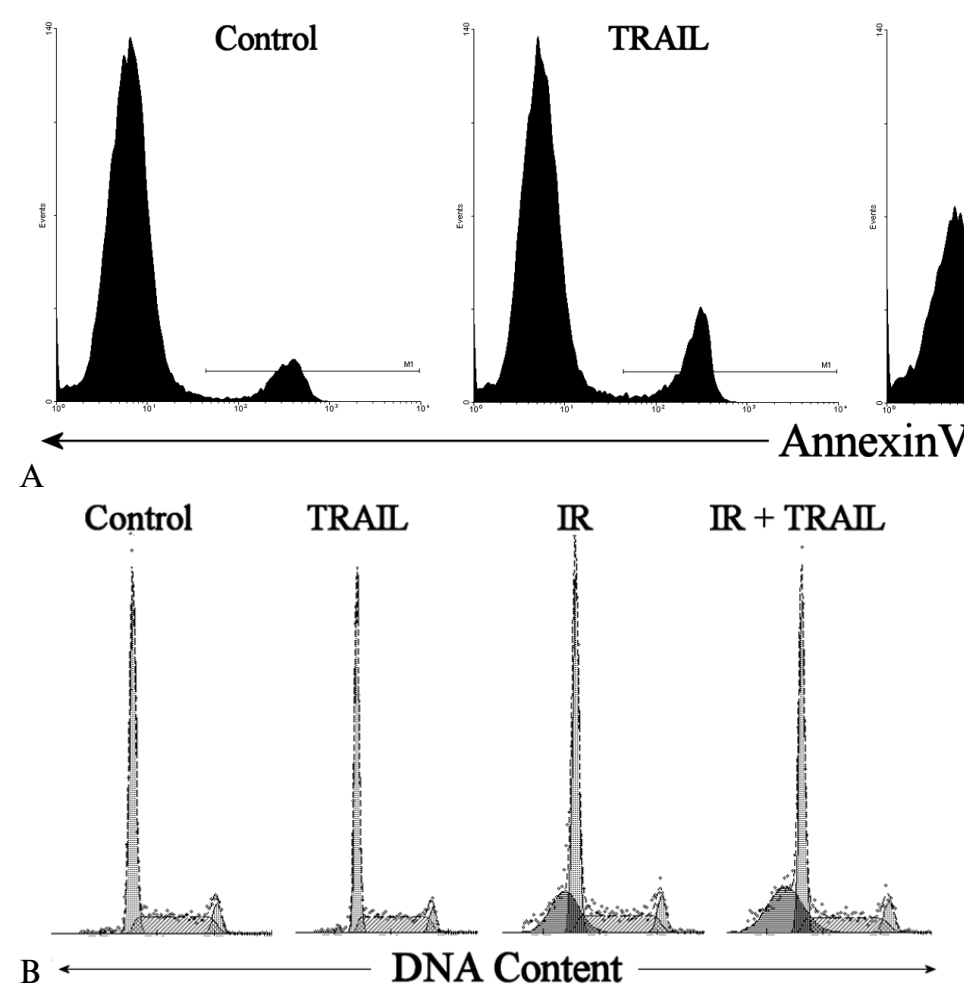

IR

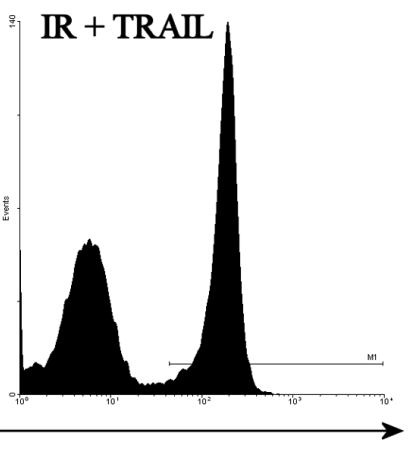

Fig. 4: Combined effect of irradiation and TRAIL on apoptosis induction $40 \mathrm{~h}$ after the irradiation (24 $h$ after TRAIL addition).

MOLT-4 cells were irradiated by the dose of $1 \mathrm{~Gy}$ and TRAIL in final concentration $100 \mathrm{ng} / \mathrm{ml}$ was added to the culture medium $16 \mathrm{~h}$ after the irradiation. $40 \mathrm{~h}$ after the the irradiation ( $24 \mathrm{~h}$ after TRAIL addition), apoptosis was detected by Annexin $\mathrm{V}$ binding $(\mathrm{A})$ and as subG1 peak in DNA content measurement (B).
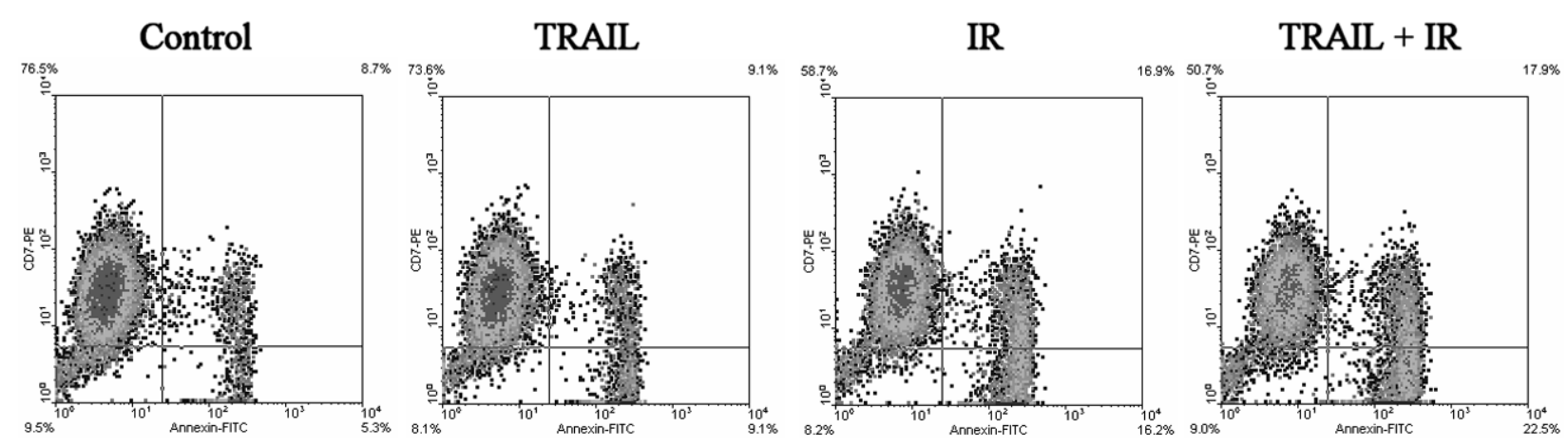

Fig. 5: Dual detection of CD7 and Annexin V binding.

MOLT-4 cells were irradiated by the dose of 1 Gy and TRAIL in final concentration $100 \mathrm{ng} / \mathrm{ml}$ was added to the culture medium $16 \mathrm{~h}$ after the irradiation. $22 \mathrm{~h}$ after the irradiation the cells were analyzed for Annexin $\mathrm{V}$ binding and CD7.

Death receptors ligands such as TRAIL have the ability to induce death in susceptible cell types, which arouses considerable interest in their therapeutical potential as antitumor drugs. TRAIL is selectively toxic to a variety of human tumor cells, and TRAIL-based agents recently entered clinical trials (5). Primary leukemia cells and established leukemia cell lines studied to date have shown variable susceptibility to TRAIL. Wen et al. (17) and our previous work (13) prove that in acute leukemia cells HL-60, U 937 and Jurkat TRAIL activates intrinsic mitochondrial pathways of apoptosis. Since the cells lack a functional p53, this activation must be p53 independent. It was also shown that p53 regulates transcription of proapoptotic receptor DR5.
Although the Apo-2L-sensitive acute leukemia cell types expressed DR5 and in HL-60 also DR4, the level of expression of these death-signaling receptors did not correlate with the sensitivity to TRAIL (17). The cells can be TRAIL-resistant not only due to low expression of DR-4/5, but also due to increased expression of caspase activation inhibitor FLIP (8). Sensitivity to TRAIL is also dependent on the amount of antiapoptic proteins from the Bcl-2 family: increased expression of $\mathrm{Bcl}-2$ a $\mathrm{Bcl}-\mathrm{x}_{\mathrm{L}}$ inhibits TRAIL-induced apoptosis (6). Defects in gene expression in many tumors (e.g. CLL has a high frequency of $\mathrm{Bcl}-2$ overexpression) are responsible for increased resistance of these cells to apoptosis induction. In HL-60 cells (high expression of 
DR5 and DR4), TRAIL application also increases radiosensitivity because it leads to a decrease in antiapototic Mcl-1 (13).

In this work we demonstrate high resistance of MOLT4 cells to TRAIL, and according to the levels of TRAIL receptor DR5 in the membrane of the cells we presume that the resistance is due to low expression of DR5.

Anitleukemic drugs that cause DNA damage and trigger intrinsic pathways of apoptosis, such as etoposide, Ara-C and doxorubicine, increase DR5 levels in tumor cells, including acute leukemia cell lines (17). One of the less common approaches in treatment of hematological malignancies is low-dose total body irradiation. The standard schedule for treatment of non-Hodgkin lymphomas consisted of giving 0.1-0.25 Gy per fraction, 1-5 times a week to a total dose of 1.5-2 Gy (14). IR damages DNA by a broad spectrum of lesions, of which the most lethal are DSB. IR is a well known activator of intrinsic apoptotic pathways. In this work we prove that the level of DR5 increases in MOLT- 4 cells after irradiation using doses of 1 and 3 Gy. The increase is apparent $6 \mathrm{~h}$ after the exposure to IR and lasts at least $24 \mathrm{~h}$. These data are supported by findings of Gong and Almasan (4), who detected an increase in DR5 mRNA in MOLT- 4 cells $8 \mathrm{~h}$ after irradiation by a lethal dose of $10 \mathrm{~Gy}$. Application of TRAIL in the time of increased DR5 positivity increases apoptosis induction despite the original resistance of MOLT- 4 cells to TRAIL. Apoptosis induction is also accompanied by loss of CD7 surface marker.

Our study demonstrates that IR in the therapeutically achievable dose of $1 \mathrm{~Gy}$ sensitizes TRAIL-resistant cells of acute T-lymphoblastic leukemia MOLT-4 to the TRAIL-induced apoptosis by increasing in death receptors for TRAIL DR5. When TRAIL is applied in the time of increased DR5 positivity, more efficient cell killing is achieved.

\section{Acknowledgement}

This work was supported by the Ministry of Education, Youth and Sports of the Czech Republic, project MSM 0021620820 .

\section{References}

1. Belka C, Schmith B, Marini P, Durand E, Rudner J, Faltin HM, Bamberg M, Schutze-Osthoff K, Budach W. Sensitization of resistant lymphoma cells to irradiation/induced apoptosis by the death ligand TRAIL. Oncogene 2001; 20:2190-6

2. Bucur O, Subrata R, Bucur MC, Almasan A. APO2 ligand-tumor necrosis factorrelated apoptosis-inducing ligand in prostate cancer therapy. Frontiers in Bioscience 2006;11:1549-68.

3. Georgakis GV, Li Y, Humphreys R, Andreeff M, O Brien S, Younes M. Activity od selective fully human agonistic antibodies to the TRAIL death receptors TRAIL-R1 and TRAIL-R2 in primary and cultured lymphoma cells: induction apoptosis and enhancement of doxorubicin - and bortezomib-induced cell death. $\mathrm{Br}$ J Haematol 2005;130:501-10.

4. Gong B, Almasan A. Apo2 ligand=TNF-related apoptosis-inducing ligand and death receptor 5 mediate the apoptotic signaling induced by ionizing radiation in leukemic cells. Cancer Res. 2000;60:5754-60.

5. Henson ES, Johnston JB, Gibson SB. The role of TRAIL death receptors in the treatment of hematological malignancies. Leukemia and Lymphoma 2008; 49:27-35.

6. Ibrado AM, Huang Y, Fang G, Bhalla K. Over expression of Bcl-2 or Bcl-XL inhibits Ara-C-induced CPP32/Yama protease activity and apoptosis of human AML HL-60 cells. Cancer Res 1996;56:4743-8.

7. Kaufmann SH, Steensma DP. On the TRAIL of a new therapy for leukemia Leukemia 2005;19:2195-202.

8. Kim K, Fisher MJ, Xu SQ, El-Deiry WS. Molecular determinants of response to TRAIL in killing of normal and cancer cells. Clin Cancer Res 2000;6:335-46.

9. Meng RD, El-Deiry WS. p53 -indipendent upregulation of KILLER /DR5 TRAIL receptor expression by glucocorticoids and interferon- $\gamma$. Exp Cell Res 2001;262: $154-69$

10. Nicholson DW. From bench to clinic with apoptosis-based therapeutic agents Nature 2000;407:810-16

11. Pan Q, Liu B, Liu J, Cai R, Wang Y, Qian C. Synergistic inductionof tumor cell death by combining cisplatin with an oncolytic adenovirus carrying TRAIL. Mol Cell Biochem 2007;304:315-23.

12. Rich T, Allen RL, Wyllie AH. Defying death after DNA damage. Nature 2000; 407:777-82.

13. Rezacova M, Vavrova J, Vokurkova D, Tichy A, Knizek J, Psutka J. The importance of abrogation of G2-phase arrest in combined effect of TRAIL and ioniying radiation. Acta Bioch Pol 2005;52:889-95.

14. Safwat A. The role of low-dose total body irradiation in treatment of nonHodgkin's lymphoma: a new look at an old method. Radiother Oncol 2000; 56:1-8.

15. Sheridan JP, Marsters SA, Pitti RM, Gurney A, Skubatch M, Baldwin D, Ramakrishnan L, Gray CL, Baker K, Wood WI, Goddard AD, Godowski P, Ashkenazi A. Control of TRAIL -induced apoptosis by a family of signaling and decoy receptors. Science 1997;277:818-21.

16. Wang S, El-Deiry WS. TRAIL and apoptosis induction by TNF-family death receptors. Oncogene 2003;22:8628-33.

17. Wen J, Ramadevi N, Nguyen D, Perkins C, Worthington E, Bhalla K. Antileukemic drugs increase death receptor 5 levels and enhance Apo-2L-induced apoptosis of human acute leukemia cells. Blood 2000;96:3900-6.

18. Yagita H, Takeda K, Hazakawa Y, Smith MJ, Okumura K. TRAIL and its receptor as targets for cancer therapy. Cancer Sci 2004;95:777-83.

Submitted February 2008. Accepted April 2008.

\section{Corresponding author:}

Martina Rezáčová, Department of Medical Biochemistry, Faculty of Medicine in Hradec Králové, Charles University in Prague, Šimkova 870, 50038 Hradec Králové, Czech Republic, e-mail: rezacovam@lfhk.cuni.cz 